\title{
The Problems of Blind, Deaf and Poor-Seeing Students Learning Foreign Languages
}

\author{
Ilona Gorskaya \\ Russian State Specialized Arts Academy \\ Moscow, Russia \\ e-mail: gattanera2010@yandex.ru
}

\begin{abstract}
This article is dedicated to the learning of foreign languages by disabled students specializing in art. The proposed method of teaching by the author takes into consideration the limited physical abilities of students. The main forms of work include listening for the blind, and writing for the deaf.
\end{abstract}

\section{Keywords—English; disabled students; methodology}

\section{DifFICULITIES FACED BY DisABLED STUDENTS}

Disabled students often face difficulties that are difficult to imagine for a common person. For the blind and poorsighted people the world is limited to sound, which means basic communication. In a deaf person's world, gesture is the only communication means. Moving around a city can also be a problem for the blind; never mind learning a foreign language. AS Lev Vygodsky - a psycholinguistics theory founder said: "If a person managed to learn his native language, he can also learn a foreign one". [1, 26]

Foreign language may be difficult for healthy students, however it can become almost impossible for disabled students. As practice shows, blind musicians are more able to learn a foreign language. Lacking sight, they trust their hearing since their early childhood, sometimes developing it to phenomenal abilities, which cannot help resulting in music and language learning. If a common student hears in general six sounds, a blind musician distinguishes tones, intonations and language specifics which cannot be heard by a common student.

Deaf students have quite a different life. Lacking the world of sounds, they rely upon gestures, images, and mimics. They are talented in reading from the speaker's lips, but sound reproduction even in their native language becomes a trial. In this trial, gesture language masters, actors, mimics and gesture language translators must help.

\section{NATIVE LANGUAGE ACQUISITION}

Let's turn to the process of perception and sound pronunciation by a human being, speech production and communication. Lev Vygodsky writes in his book "Thinking and Speech": "Also in psychology child's speech development was studied from the perspective of sound, phonetic side development and its sense. The history of children's phonetics is studied in detail, but it seemed incapable to unite at least the elementary problem of phenomena. On the other hand, studying of children's word sense led to autonomous and independent child's thought history, which was not connected to the phonetic history of the language" (same place).

In an early childhood a child is surrounded by a great variety of sounds - the sound of the rain, bird's singing, cow's mooing, cat's mewing. One of the first fascinating, attractive and pleasant sounds is a mother's speech. A child instinctively tries to reach his mother's voice, babbling while trying to pronounce his first sounds. At first there is prattle, then single words are formed, then speech follows. But the most amazing phenomenon is the speech realization. The process of speech realization is formed by one year, when a child begins to combine sounds and notions.

For a blind person everything is different. The world is full of sounds. There are a lot of sounds, they multiply and fill the little creature's world. But... Alas, the world of sounds is not associated to the world of images; a word does not become an idea. A blind person orients more to his internal world more than to the external one. Here the phenomenon of music gift appears. A compensatory mechanism helps a blind person to master his hearing to perfection. Even those who lose their eyesight in adulthood become more sensitive to the sound world, and begin feeling the music and the outside world deeper and finer.

\section{DisABLED AND COMMON STUDENTS LEARNING TOGETHER}

From the linguistic point of view a music gift phenomenon helps a lot to a language student. There are a lot of opportunities for the listening of different music compositions, notes and songs, learning the language by songs and music. A teacher in his practice often uses foreign repertoire, dialogues, and radio programs - The Beatles and Queen songs are used in his classes. All this positively impacts a learning process and foreign speech absorption.

In an inclusive education form, where healthy students study together with poor-sighted and poor-hearing, the communication factor is immensely important. There are healthy, blind, and deaf students. A special role is given to tolerance and patience. On one hand a presence of a disabled student creates difficulties, and makes a group's life 
more difficult, while on the other hand it makes the world brighter and more interesting.

Among disabled students there are a lot of talented musicians, actors, translators, and teachers. An ability to hear a sound where it is not heard by the others, to distinguish a person's character by the rhythm and walking manner is definitely a treasure. Among students there are professionals able to distinguish and reproduce not only one, but two, three and four languages.

So, what are the priorities in the separate and inclusive education?

A. In the separate education the main accent is put upon the student's hearing abilities. Discs, songs, texts, dialogues, transmissions, and interview may be used.

B. Joint film watching allows the seeing students to watch a picture and the deaf ones to hear a sound.

C. Sometimes when learning a foreign language by the blind and poor-seeing students a teacher may use different examples just to get the feeling of it. For example, when learning the fruits, real apples, oranges, and lemons may be used.

D. In some cases Brail's system adapted books are recommended for usage.

E. Inclusive education communication plays the leading role. Role games, dialogues, verses help even at the first stages of education.

The Nero-linguistic programming (NLP) system divides all people into visuals, audials and kinesthetics.

\section{THE TYPES OF LEANERS}

$90 \%$ of people perceive information through the eyesight. This advantage is used by the standard school system, which teaches a school child to orient by a picture and a text, but not a sound. Many students, oriented to the external perception, become artists, designers, and illustrators.

The audial's leading instrument is an ear. They are more oriented to the world of sound, human voice, and intonation, and are more prone to music and feeling the speech nuances. If a child's ability to hear is noticed, there is a good chance that a musician, an actor or a declaratory will grow.

Kinesthetics are a minor group. Almost $100 \%$ of the earth's population orients to the body perception. Mainly these people are those whose life is connected to art. Besides, there are a lot of disabled people whose leading apparatus is a sensation. For instance, blind students use hands to study an object on the table or touch a person in the street.

All this knowledge may be applied in the methodology approach for language teaching. For instance, the visuals (mainly artists) are prone to get information from the visual channel. Why not to use it to offer them pictures? Audials (mainly musicians) perceive information by ear. Why not use this advantage to offer them discs and radio programmes? Kinesthetics are lost in the world of touch: massage and physical exercises may help. This system may successfully be used in foreign language teaching practice. It is easy to define a human perception type with the help of some tests. In the future NLP system will help to pay more attention to listening, cards, and gestures.

The greatest difficulty in foreign language teaching is the hearing problems'students. Unlike common students, the world of sound is closed for them, which represents the main difficulty in learning language - where the main principle is intonation and listening. A deaf student often makes mistakes in writing, even in his native language. For a teacher the main difficulty is interaction with a student, bringing information to his mind.

Here is a description of a deaf man by Boris Pasternak in his "Doctor Zhivago" novel:

"A young man was a hunter. He was extremely talkative and hurried to join the doctor's conversation with a pleasant smile. At the same time he literally watched the doctor's mouth. The young man had an unpleasantly high voice, which rose to a metallic falsetto. Another eccentricity: obviously a Russian, one vowel, "u" in particular, he pronounced in an extremely peculiar way. He softened it like a French " $u$ " or a German "Umlaut". Besides, this broken "u" cost him a great labour, he pronounced it with a great effort, screaming a bit, pronounced this sound louder than the others. Almost at the very beginning of the conversation he shocked Yuri Andreevich by such a phrase: "Yesterday morning I went to hunt ducks" (ootro is "morning" in Russian, ootka is a "duck" - I.G.). Some moments, when he checked himself, he forgot this peculiarity, but as soon as he forgot it, it appeared again. "What the hell?" - thought Zhivago, - "something familiar, something read. Me, as a doctor, should have know it, but it slipped my mind. Some brain phenomenon, producing articulation defect. But this whining is so ridiculous that one can hardly stay serious. It is impossible to talk. I would better climb upstairs and lay down" [3] (translated by the author).

In the morning Zhivago learned his fellow-passenger's defect and learned that he was Gartman`s school graduate. This episode proves that with the correct teaching hearing defects may be practically invisible.

In this context a role of the gesture language translator and teacher is important. A gesture language translator facilitates communication with the outside world, sometimes discovering it again.

Deaf students often become talented artists, designers, and architects. They are more oriented to the inside world. Nevertheless, living in society they have to communicate with the world of the hearing: to visit the seminars, foreign events, and to communicate with the foreign students. That is why they have language classes.

\section{Modern TeChNOLOGY AND LANGUAGE AQCUISITION}

Of course, we do not speak about training synchrony translators. The teacher's main task in this case is to teach a 
written speech, written translation and written communication on elementary level. For this purpose it is recommended to use the following methods:

\section{A. Explain the main positions of foreign language} grammar with the help of a sign language translator and ask the students to make them at home;

B. Provide the maximum exercises for translation with the help of a dictionary;

C. Control the grammar terms and grammar nuances;

D. Use active games at a class, using cards with objects and matching them;

E. Internet communication, letters exchange will also be useful for a teacher and a student.

In general, deaf students education is equal to a correspondence teaching system at a professional language college.

Special attention should be given to modern technologies in foreign languages teaching. In our quickly changing world technologies help human beings in life and at work. That is why classes should be equipped with lingo-phone devices and speech recorders (compact disk players and recorders, DVDs, etc.) Modern systems also suggest using the Internet, education programmes, and Skype communication. The last is particularly special for disabled people: they may learn the language without leaving home.

A researcher V.V. Dovbenko writes: "It is absolutely obvious that teaching with the help of computer takes away a very acute problem of education for the disabled people. Modern computer unites a TV set, a VHR, a projector, demonstration material and many others. It makes a pupil's activity easier, more intense and interesting.

Distance education is a way of teaching process organization, based upon modern IT system usage, and allowing the providence of a distant education without a real contact between a teacher and a student. Distance teaching systems are available at any time and any place, independent on place of living. It is enough to have Internet access. Such education allows study in your own rhythm and style depending on individual needs and personal specifics. For limited abilities children this is a way to the new world, a chance to realize themselves and their needs, to grow and develop depending on their wishes, in spite of anything. [4]

\section{CONCLUSION}

For a foreign language teacher disabled student teaching is a challenge. On one hand their limitations do not allow a teacher to show all the beauty of the language, on the other hand they inspire a teacher to study and to learn the new ways to study the world and bring it to the students.

\section{REFERENCES}

[1] Vygodsky L.S. Thinking and Speech. 3rd edition. Moscow, Labyrinth, 1999.
[2] Gozman L.Ya., Shestopal E.B. Distant education on the verge of the XXIst century. Moscow, Mysl', 1999.

[3] Pasternak B.L. Doctor Zhivago. Novy Mir magazine. Moscow, 1989.

[4] Dovbenko V.V. Distant education of English of limited abilities children and disabled children at school and at home. http://nsportal.ru

[5] Kulikov V.Ya. Innovation technologies development of foreign languages teaching at school of Volgograd region. http://www.diplomat.wol.ru

[6] Linden A. NLP Bible. Psychotechnologist's Table Book. Moscow, Prime Eurosign, 2010.

[7] A Table Book of a Foreign Language Teacher/Reference Book. $2^{\mathrm{Nd}}$ edition. Minsk, Vyshaya Shkola, 1996. 